\title{
An Improved Algorithm for Calculating Friction Force and Torque in Involute Helical Gears
}

\author{
Lin Han, Wentie Niu, Dawei Zhang, and Fujun Wang \\ School of Mechanical Engineering, Tianjin University, Tianjin 300072, China \\ Correspondence should be addressed to Wentie Niu; niuwentie@tju.edu.cn \\ Received 17 January 2013; Revised 30 January 2013; Accepted 31 January 2013 \\ Academic Editor: Claude Lamarque
}

Copyright (C) 2013 Lin Han et al. This is an open access article distributed under the Creative Commons Attribution License, which permits unrestricted use, distribution, and reproduction in any medium, provided the original work is properly cited.

\begin{abstract}
Time varying frictional force and torque are one of the main exciting sources of vibration in helical gears. This paper presents an approach to determine the friction force and torque in involute helical gears considering nonuniform load distribution along contact lines. An analytical load distribution model is employed and extended to obtain the load per unit of length along contact lines. Friction force and torque models under nonuniform assumption are derived. Comparisons of the determined friction force and torque with the results from uniform assumption are made. In addition, the differences between constant friction coefficient and varying coefficient are revealed. Moreover, two typical design cases of helical gears are studied. Results show that the fluctuations of friction force and torque under uniform assumption are more significant than those under nonuniform assumption in sample I for a single tooth, but less significant for the sum of those of the three teeth, while in sample II, the fluctuations under uniform assumption are less significant than those under nonuniform assumption. The friction coefficient induced difference is negligible compared with the difference induced by load distribution assumptions.
\end{abstract}

\section{Introduction}

Gears have been widely used in many fields, such as heavyduty machines, helicopters, marine ships, and machine tools. The noise and vibration significantly affect the efficiency and reliability in these applications. Besides the time-varying mesh stiffness, damping, static transmission error, and backlash, the time-varying friction force and torque between meshing tooth pairs are also important exciting sources of the noise and vibration in gear pairs.

A number of literature works concerning the effect of friction on dynamics of spur gears could be found. The finite element method was employed in [1] to model the elastic properties of spur gear pair and to analyze the effects of friction. It was concluded that the input and output torque did not remain constant when frictional effects were taken into account, and a time-varying dynamic transmission error was induced. The influence of tooth friction on gear dynamics, where average mesh stiffness per unit of contact length, uniform normal load distributions, and constant coefficient of friction have been assumed, has been investigated and the results revealed the potentially significant contribution of tooth friction to gear vibration and noise. Sliding friction accounts for most of the losses at low-medium speeds while rolling friction becomes more significant at high speed $[2,3]$.

The authors of $[4,5]$ presented the procedure to obtain the friction force and torque. The author of [4] has presented a 16-DOF dynamic model for a spur gear pair by incorporating friction effects between meshing teeth. The coefficient of friction was assumed to vary linearly with shaft angle, and the friction force is calculated from the normal meshing force comprising both mesh stiffness and damping values. A linear time-varying and a nonlinear time-varying dynamics for spur gear systems were modeled to investigate the effects introduced by friction, with different considerations of coefficient of friction. And then the authors gave the semianalytical solution and numerical solution, respectively [5]. The authors of $[6,7]$ presented an improved MDOF spur gear pair model with alternate sliding friction formulations, and the simulations indicated small differences when different sliding friction formulations were employed.

Compared with spur gear, the length of contact line for a tooth in helical gear varies with different meshing positions of pinion and gear, which will excite vibrations especially in 
helical gear system [8]; the load distribution along the contact line is not uniform, which is different from that of spur gear pairs. It was shown in [9] that the fluctuations of friction force and torque induced more significant effects than the effects introduced by the values of friction force and torque in gear system. The author of [10] proposed a new analytical model for helical gears that characterized the contact plane dynamics and captured the velocity reversal at the pitch line due to sliding friction, with the assumption of constant mesh stiffness per unit length along contact line. A 12-DOF dynamic model with the inclusion of friction force and torque was established, and a simplified 6-DOF model was proposed for dynamics analysis. Kar and Mohanty $[11,12]$ presented an algorithm for determination of time-varying frictional force and torque at meshing teeth and the bearings in a helical gear system, which was an extension of the method proposed in [4] for spur gears. One of the assumptions in their work is the uniform load distribution along contact lines.

The objective of this paper is to reveal the differences between uniform and nonuniform load distribution along contact lines while calculating friction force and torque for helical gears. The approach is an extension of the work presented by [11] for helical gears. Firstly, the variation of contact line is presented. Then an analytical load distribution model for involute helical gears proposed by Pedrero et al. [13] is employed and extended to get the normal load along contact lines. With the assumption of constant friction coefficient, both friction force and torque at each contact point are calculated and compared with the results from uniform load distribution assumption. Moreover, another typical design sample is studied and the results are presented. The influences of different friction coefficient models on the resultant force and torque are also investigated.

\section{Mathematical Model}

2.1. Time-Varying Length of Contact Lines. Figure 1 shows the meshing schematic of an involute helical gear pair. The contact lines are formed by the engaged teeth of pinion and gear, and all lie in the inner common tangent plane of the two base cylindrical surfaces of pinion and gear. The angle between the gear axis and instantaneous contact line is $\beta_{b}$. Typically, the total contact ratio $\varepsilon$ of helical gears is $2<\varepsilon=$ $\varepsilon_{\alpha}+\varepsilon_{\beta}<3$, which means that there are two or three teeth in simultaneous contact.

The following are denoted:

$$
\begin{aligned}
& d_{\alpha}=\operatorname{rem}\left(\varepsilon_{\alpha}, 1\right), \\
& d_{\beta}=\operatorname{rem}\left(\varepsilon_{\beta}, 1\right),
\end{aligned}
$$

where the function $\operatorname{rem}\left(\varepsilon_{\alpha}, 1\right)$ means the decimal fraction of transverse contact ratio $\varepsilon_{\alpha}$, and $\operatorname{rem}\left(\varepsilon_{\beta}, 1\right)$ means the decimal fraction of axial contact ratio $\varepsilon_{\beta}$. Two typical design samples will be investigated as follows:

$\left(d_{\alpha}+d_{\beta}<1\right)$ : the sum of residuals of transverse and axial contact ratios is smaller than one;

$\left(d_{\alpha}+d_{\beta}>1\right)$ : the sum of residuals of transverse and axial contact ratios is larger than one.

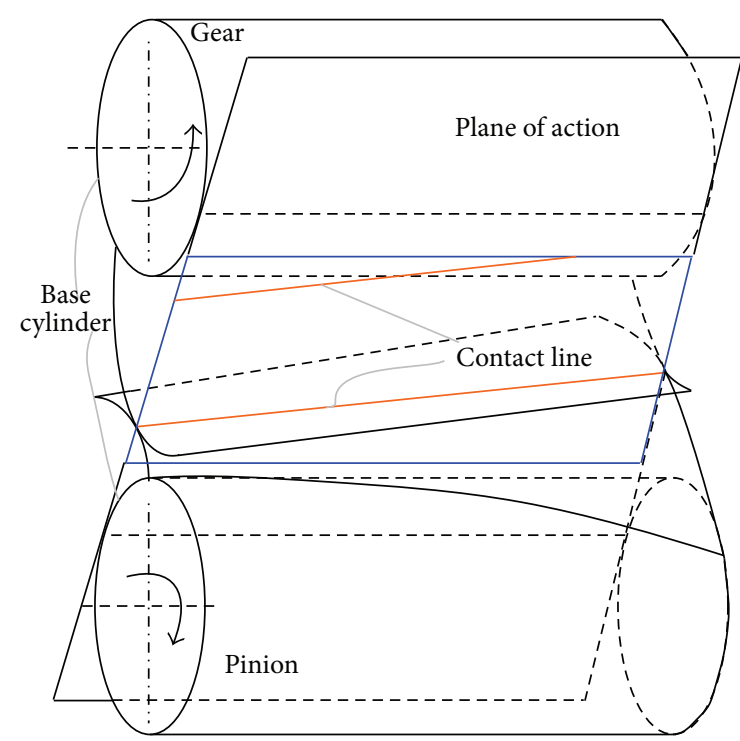

FIGURE 1: Meshing of a helical gear pair.

The variations of contact lines for both samples are shown in Figure 2.

For a single tooth, the contact line increases gradually before it reaches the maximum. Then the length of contact line remains constant for a while, after which the contact line decreases gradually as the pinion or gear further rotates until finishing meshing. In Figure 2(a), the length reaches its maximum value $f \operatorname{cosec} \beta_{b}$ at point $C$ and keeps the value till point D. In Figure 2(b), the contact line keeps the maximum value $b \sec \beta_{b}$ during the mesh period from point $\mathrm{D}$ to point C.

The individual and total lengths of contact lines for three teeth in one transverse pitch travel are expressed as follows.

(1) Sample I $\left(d_{\alpha}+d_{\beta}<1\right)$

$$
\begin{aligned}
L_{0}(t) & =\frac{r_{b} \omega_{p} t}{\sin \beta_{b}}, \quad 0 \leq t<T, \\
L_{1}(t) & =\frac{\left(p_{t}+r_{b} \omega_{p} t\right)}{\sin \beta_{b}}, \quad 0 \leq t<t_{11} \\
& =\frac{f}{\sin \beta_{b}}, \quad t_{11} \leq t<t_{12} \\
& =\frac{\left(b \cdot \tan \beta_{b}+f-p_{t}-r_{b} \omega_{p} t\right)}{\sin \beta_{b}}, \quad t_{12} \leq t<T, \\
L_{2}(t) & =\frac{\left(b \cdot \tan \beta_{b}-\left(r_{b} \omega_{p} t+2 p_{t}-f\right)\right)}{\sin \beta_{b}}, \quad 0 \leq t<t_{21} \\
& =0, \quad t_{21} \leq t<T \\
L(t) & =L_{1}(t)+L_{2}(t)+L_{3}(t) .
\end{aligned}
$$




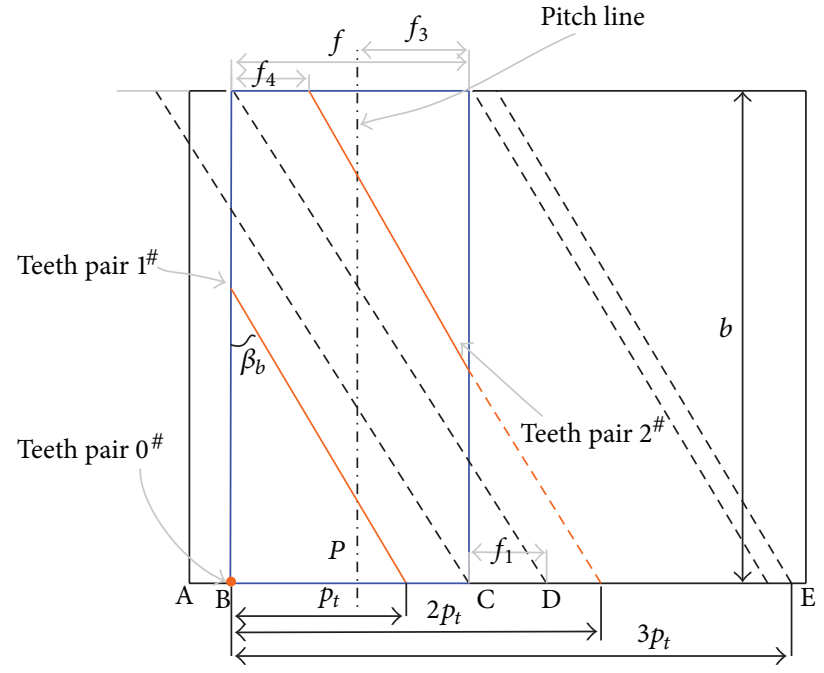

(a)

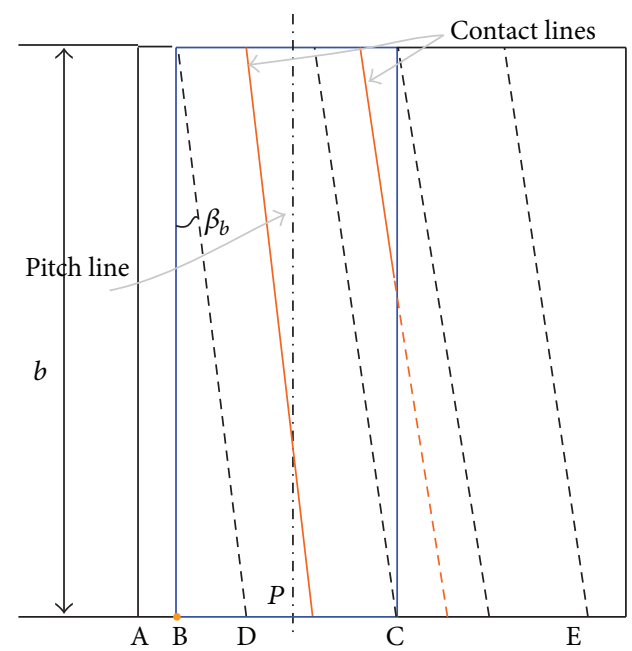

(b)

FIGURE 2: Contact line variations: (a) sample I, (b) sample II.

(2) Sample II $\left(d_{\alpha}+d_{\beta}>1\right)$

$$
\begin{aligned}
L_{0}(t) & =\frac{r_{b} \omega_{p} t}{\sin \beta_{b}}, \quad 0 \leq t<t_{0} \\
& =\frac{b}{\cos \beta_{b}}, \quad t_{0} \leq t<T, \\
L_{1}(t) & =\frac{b}{\cos \beta_{b}}, \quad 0 \leq t<t_{11} \\
& =\frac{\left(b \tan \beta_{b}-\left(r_{b} \omega_{p} t-\left(\varepsilon_{\alpha}-1\right) p_{t}\right)\right)}{\sin \beta_{b}}, \quad t_{11} \leq t<T \\
L_{2}(t) & =\frac{\left(b \tan \beta_{b}-\left(r_{b} \omega_{p} t+\left(2-\varepsilon_{\alpha}\right) p_{t}\right)\right)}{\sin \beta_{b}}, \quad 0 \leq t<t_{21} \\
& =0, \quad t_{21} \leq t<T, \\
L(t) & =L_{1}(t)+L_{2}(t)+L_{3}(t),
\end{aligned}
$$

where $v=r_{b} \omega_{p}, t_{0}=b \tan \beta_{b} / v, t_{11}=\left(f-p_{t}\right) / v, t_{21}=$ $\left(f+b \cdot \tan \beta_{b}-2 p_{t}\right) / v$,

$$
t_{12}=\frac{\left(b \cdot \tan \beta_{b}-p_{t}\right)}{v}, \quad T=\frac{p_{t}}{v} .
$$

2.2. Load per Unit of Length along Contact Lines. Though uniform load distribution is assumed in most of the literature, the load per unit of length varies along contact lines. In this paper, to get the real load distribution in involute helical gears, an analytical load distribution model is employed.

The expression is given by

$$
f\left(\zeta, \zeta_{0}\right)=\frac{\varepsilon_{\beta} \cos \beta_{b}}{b} \frac{v(\zeta)}{I_{v}\left(\zeta_{0}\right)} F,
$$

where function $f\left(\zeta, \zeta_{0}\right)$ represents the load per unit of length applied to the point of contact line corresponding to $\zeta$ at the moment in which the reference transverse section is in contact at the point $\zeta_{0}$ and $F$ is the applied load. More details could be found in [13].

In this paper, to get the load per unit of length along contact lines, each contact line is divided into segments along the axis of gear and the expression for the normal load applied on the $i$ th segment of $k$ th tooth at $j$ th meshing instant is written here as

$$
\begin{gathered}
f_{k}\left(i_{k}, j\right)=\frac{\varepsilon_{\beta} \cos \beta_{b}}{b} \frac{v\left(\zeta_{i_{k}}\left(t_{j}\right)\right)}{I_{v}\left(\zeta_{0, k}\left(t_{j}\right)\right)} F, \quad i_{k}=1,2, \ldots, N_{j, k}, \\
k=0,1,2, j=1,2, \ldots, N_{t} .
\end{gathered}
$$

As for time-varying length of contact lines, $N_{j, k}$ is the number of segments for each tooth in contact, varying with meshing positions.

Parameters in (6) are given by

$$
\begin{gathered}
v\left(\zeta_{i_{k}}\left(t_{j}\right)\right)=\cos \left[b_{0}\left(\zeta_{i_{k}}\left(t_{j}\right)-\frac{\varepsilon_{\alpha}}{2}\right)\right], \\
b_{0}=\left[\frac{1}{2}\left(1+\frac{\varepsilon_{\alpha}}{2}\right)^{2}-1\right]^{-1 / 2}, \\
\zeta_{i_{k}}\left(t_{j}\right)=\xi_{i_{k}}\left(t_{j}\right)-\xi_{\text {inn }} \\
\xi_{\text {inn }}=\frac{z}{2 \pi} \sqrt{\frac{r_{a}^{2}}{r_{b}^{2}}-1-\varepsilon_{\alpha}} \\
\xi_{i_{k}}\left(t_{j}\right)=\frac{z}{2 \pi} \sqrt{\frac{r_{i_{k}, j}^{2}}{r_{b}^{2}}-1} \\
I_{v}\left(\zeta_{0, k}\left(t_{j}\right)\right)
\end{gathered}
$$




$$
\begin{gathered}
=\frac{1}{b_{0}} \sum_{n=0}^{E_{\gamma}}\left[\sin \left[b_{0}\left(\zeta_{n, \text { sup }}-\frac{\varepsilon_{\alpha}}{2}\right)\right]\right. \\
\left.-\sin \left[b_{0}\left(\zeta_{n, \text { inf }}-\frac{\varepsilon_{\alpha}}{2}\right)\right]\right] \\
\zeta_{n, \text { sup }}=\zeta_{0, k}\left(t_{j}\right)+n+\varepsilon_{\alpha}-\min \left(\zeta_{0, k}\left(t_{j}\right)+n, 0\right) \\
-\max \left(\zeta_{0, k}\left(t_{j}\right)+n, \varepsilon_{\alpha}\right) \\
\zeta_{n, \text { inf }}=\zeta_{0, k}\left(t_{j}\right)+n-\varepsilon_{\beta}+\varepsilon_{\alpha}-\min \left(\zeta_{0, k}\left(t_{j}\right)+n-\varepsilon_{\beta}, 0\right) \\
-\max \left(\zeta_{0, k}\left(t_{j}\right)+n-\varepsilon_{\beta}, \varepsilon_{\alpha}\right)
\end{gathered}
$$

$\xi_{\text {inn }}$ denotes the profile parameter corresponding to the inner point of contact of the pinion, and $r_{i_{k}, j}$ is the distance from the applied force point to the center of gear or pinion in the transverse plane shown in Figure 3.

The expressions for parameters $\zeta_{0, k}\left(t_{j}\right)$ and $\zeta_{i_{k}}\left(t_{j}\right)$ for three teeth in a mesh cycle are given by

$$
\begin{gathered}
\zeta_{0,0}\left(t_{j}\right)= \begin{cases}0, & t_{j} \leq t_{0}, \\
\frac{z \cdot \omega_{p}}{2 \pi}\left(t_{j}-t_{0}\right), & t_{0}<t_{j} \leq T,\end{cases} \\
\zeta_{0,1}\left(t_{j}\right)=\frac{z}{2 \pi r_{b p}}\left(p_{t}-b \cdot \tan \beta_{b}+v \cdot t_{j}\right), \\
\zeta_{0,2}\left(t_{j}\right)= \begin{cases}\frac{z}{2 \pi r_{b p}}\left(2 p_{t}-b \cdot \tan \beta_{b}+v \cdot t_{j}\right), & t_{j} \leq t_{2}, \\
0, & t_{2}<t_{j} \leq T, \\
\zeta_{i_{k}}\left(t_{j}\right)=\frac{z}{2 \pi r_{b p}}\left(R_{e}\left(i_{k}, j\right)-A B\right),\end{cases}
\end{gathered}
$$

respectively, where $R_{e}\left(i_{k}, j\right)$ is the radii of curvature given in the following section.

2.3. Friction Force. The direction of friction force is perpendicular to the line of action in the transverse plane parallel to the cross section of the gear and pinion, and perpendicular to the contact lines in the plane of action. The force is assumed to be positive when the contact point on the contact line is above the pitch line and negative otherwise. Hence, the friction force of $i$ th segment of $k$ th tooth of pinion at $j$ th meshing instant could be given by

$$
F_{k}\left(i_{k}, j\right)=\mu \cdot f_{k}\left(i_{k}, j\right) \cdot \Delta l
$$

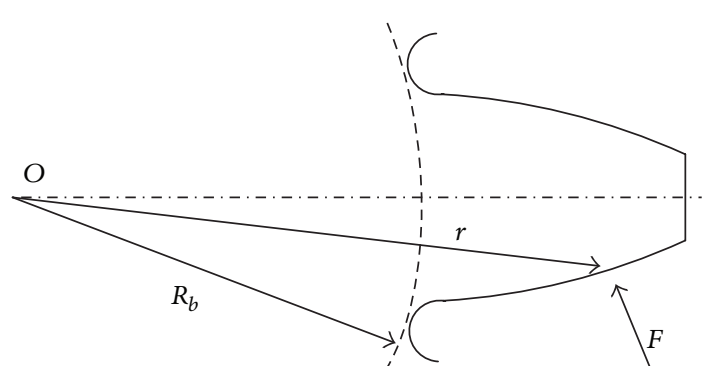

FIGURE 3: Geometrical parameter of an involute tooth.

where $\mu$ is the constant coefficient of friction, and $\Delta l$ is the length of a segment. The friction force of $k$ th tooth at $j$ th meshing instant is expressed as

$$
\begin{array}{rl}
F_{0}\left(t_{j}\right)= & -\mu \cdot\left(\sum_{i_{0}=1}^{N_{00}} f_{0}\left(i_{0}, j\right)\right) \cdot \Delta l \quad 0 \leq t_{j}<\frac{\left(f-f_{3}\right)}{v} \\
= & -\mu \cdot\left(\sum_{i_{0}=1}^{N_{01}} f_{0}\left(i_{0}, j\right)-\sum_{i_{0}=N_{01}+1}^{N_{0, j}} f_{0}\left(i_{0}, j\right)\right) \cdot \Delta l \\
F_{1}\left(t_{j}\right)=-\mu \cdot\left(\sum_{i_{1}=1}^{N_{11}} f_{1}\left(i_{1}, j\right)-\sum_{i_{1}=N_{11}+1}^{N_{1, j}} f_{1}\left(i_{1}, j\right)\right) \cdot \Delta l \\
v & 0 \leq t_{j}<T, \\
F_{2}\left(t_{j}\right)=-\mu \cdot\left(\sum_{i_{2}=1}^{N_{21}} f_{2}\left(i_{2}, j\right)-\sum_{i_{2}=N_{21}+1}^{N_{2, j}} f_{2}\left(i_{2}, j\right)\right) \cdot \Delta l & 0 \leq t_{j}<T,
\end{array}
$$

where the function round $(x)$ gets the integer nearest to $x$. And

$$
\begin{aligned}
& N_{00}=\operatorname{round}\left(\frac{L_{1}}{\Delta l}\right), \\
& N_{01}=\operatorname{round}\left(\frac{L_{11}}{\Delta l}\right), \\
& N_{11}=\operatorname{round}\left(\frac{L_{21}}{\Delta l}\right), \\
& N_{21}=\operatorname{round}\left(\frac{L_{31}}{\Delta l}\right) .
\end{aligned}
$$

The contact line segments divided by pitch line in sample I, shown in Figure 4, are given by 


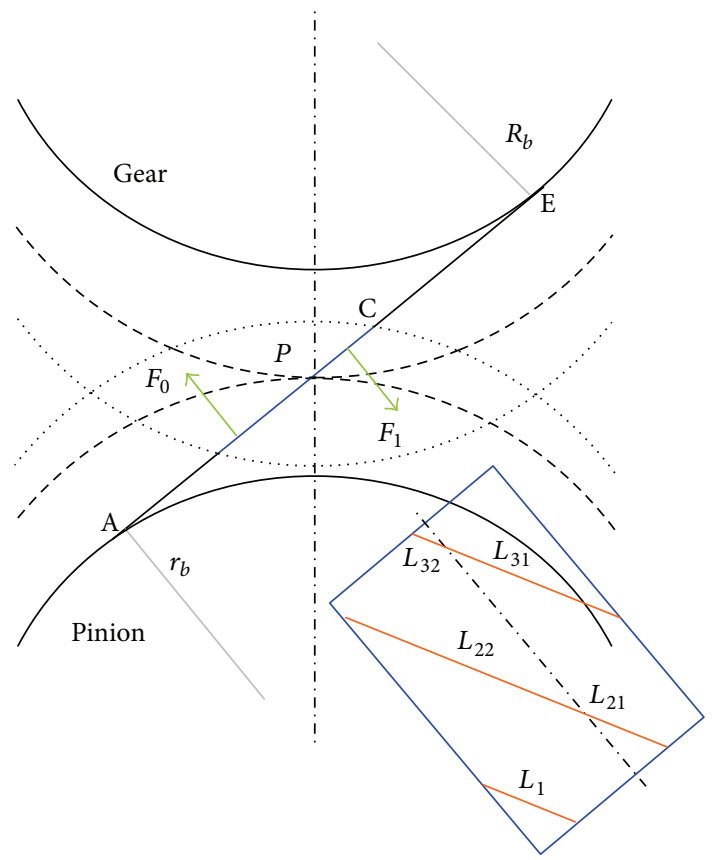

FIGURE 4: Schematic of friction force direction.

$$
\begin{aligned}
& L_{12}=\frac{\left(f-f_{3}\right)}{\sin \beta_{b}}, \\
& L_{11}=L_{1}-L_{12}, \\
& L_{22}=\frac{\left(f-f_{3}\right)}{\sin \beta_{b}}, \quad 0 \leq v t<\left(f+f_{1}-p_{t}\right), \\
& L_{21}=L_{2}-L_{22}, \\
& L_{21}=\frac{f_{3}}{\sin \beta_{b}}, \quad\left(f+f_{1}-p_{t}\right) \leq v t<p_{t}, \\
& L_{22}=L_{2}-L_{21}, \\
& L_{31}=\frac{f_{3}}{\sin \beta_{b}}, \quad 0 \leq v t<\left(f-\left(f_{3}+f_{4}\right)\right), \\
& L_{32}=L_{3}-L_{31}, \\
& L_{31}=L_{3} \quad\left(f-\left(f_{3}+f_{4}\right)\right) \leq v t<p_{t} .
\end{aligned}
$$

Similarly, the contact line segments in sample II are derived as

$$
\begin{gathered}
L_{11}=\left(v \cdot t_{j}-\left(f-f_{3}\right)\right) \operatorname{cosec} \beta_{b}, \\
L_{12}=L_{1}-L_{11}, \\
L_{21}=\left(p_{t}-\left(f-f_{3}\right)+v \cdot t_{j}\right) \operatorname{cosec} \beta_{b}, \\
0 \leq t_{j}<\frac{\left(b \cdot \tan \beta_{b}-f_{3}+f-p_{t}\right)}{v}, \\
L_{21}=L_{2}, \quad \frac{\left(b \cdot \tan \beta_{b}-f_{3}+f-p_{t}\right)}{v} \leq t_{j}<T,
\end{gathered}
$$

$$
\begin{gathered}
L_{22}=L_{2}-L_{21}, \\
L_{31}=L_{3}, \quad 0 \leq t<T, \\
L_{32}=L_{3}-L_{31} .
\end{gathered}
$$

Accordingly, the total friction force for one transverse pitch travel is obtained as

$$
F_{f}\left(t_{j}\right)=\sum_{k=0}^{\text {floor }(\varepsilon)} F_{k}\left(t_{j}\right), \quad 0 \leq t_{j}<T .
$$

Function floor $(\varepsilon)$ gets the maximum integer smaller than $\varepsilon$.

2.4. Frictional Torque. The formulations for friction torque of sample I under uniform load assumption could be found in [14], while the formulations for each tooth in sample II under uniform assumption are derived as

$$
\begin{aligned}
& T_{f 0}=\mu \frac{F}{L} L_{1}\left(L_{\mathrm{AC}}-\left(f-\frac{v t}{2}\right)\right) \quad 0 \leq v t<b \tan \beta_{b} \\
& =\mu \frac{F}{L} L_{1}\left(L_{\mathrm{AC}}-\left(f-\left(v t-b \tan \beta_{b}+\frac{b \tan \beta_{b}}{2}\right)\right)\right), \\
& b \tan \beta_{b} \leq v t<\left(f-f_{3}\right) \\
& =\mu \frac{F}{L} L_{12}\left(L_{\mathrm{AC}}-\left(\frac{f-f_{3}-\left(v t-b \tan \beta_{b}\right)}{2}+f_{3}\right)\right) \\
& -\mu \frac{F}{L} L_{11}\left(\mathrm{AC}-\left(f_{3}-\frac{v t-\left(f-f_{3}\right)}{2}\right)\right), \\
& \left(f-f_{3}\right) \leq v t<p_{t}, \\
& T_{f 1}=\mu \frac{F}{L} L_{22}\left(L_{\mathrm{AC}}-\frac{\left(f-f_{3}\right)-\left(p_{t}-b \tan \beta_{b}\right)-v t}{2}+f_{3}\right) \\
& -\mu \frac{F}{L} L_{21}\left(L_{\mathrm{AC}}-\left(f_{3}-\frac{p_{t}-\left(f-f_{3}\right)+v t}{2}\right)\right), \\
& 0 \leq v t<b \tan \beta_{b}-\left(p_{t}-\left(f-f_{3}\right)\right) \\
& =-\mu \frac{F}{L} L_{21} \\
& \times\left(L_{\mathrm{AC}}-\left(f-\left(\frac{b \tan \beta_{b}}{2}+v t+p_{t}-b \tan \beta_{b}\right)\right)\right), \\
& b \tan \beta_{b}-\left(p_{t}-\left(f-f_{3}\right)\right) \leq v t<\left(f-p_{t}\right) \\
& =-\mu \frac{F}{L} L_{21}\left(L_{\mathrm{AC}}-\frac{b \tan \beta_{b}-\left(v t-\left(f-p_{t}\right)\right)}{2}\right) \text {, } \\
& \left(f-p_{t}\right) \leq v t<p_{t}, \\
& T_{f 2}=-\mu \frac{F}{L} L_{3}\left(L_{\mathrm{AC}}-\frac{f-\left(p_{t}-b \tan \beta_{b}\right)-p_{t}-v t}{2}\right) \text {, } \\
& 0 \leq v t<f+b \tan \beta_{b}-2 p_{t} \\
& =0, \quad f+b \tan \beta_{b}-2 p_{t} \leq v t<p_{t} \text {. }
\end{aligned}
$$




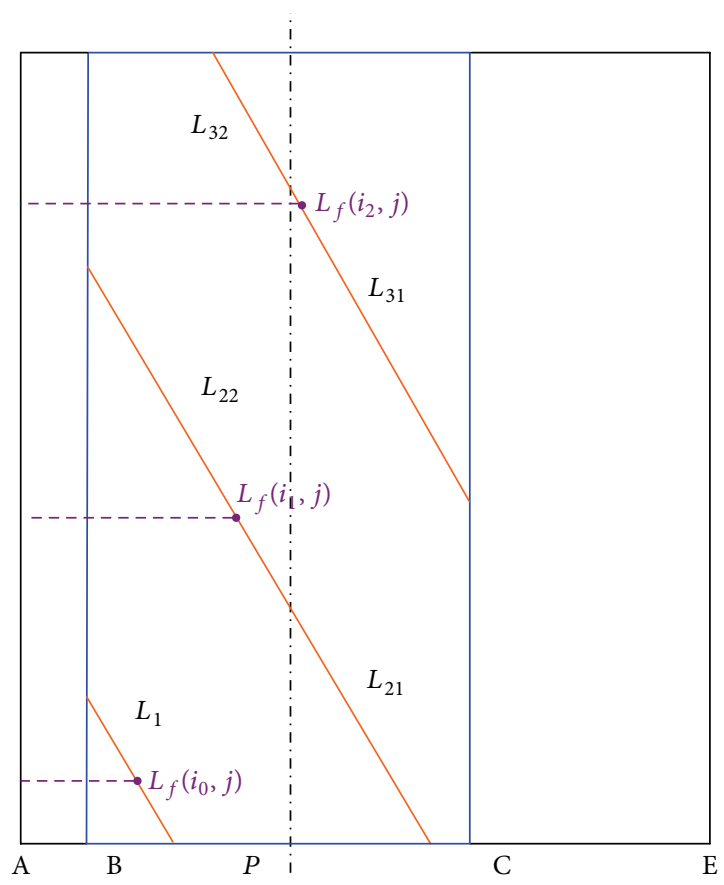

FIGURE 5: Frictional torque arm.

The following are the derivations of friction torque under nonuniform load assumption. The friction moment arm is equal to the radii of curvature in entrainment direction at each contact point, as shown in dashed lines in Figure 5. According to the involute profile of a tooth, the radii of curvature of $i$ th segment of $k$ th tooth pair of pinion at $j$ th meshing instant in the transverse plane could be written as

$$
\begin{aligned}
R_{e}\left(i_{0}, j\right)= & L_{\mathrm{AB}}+i_{0} \cdot L_{0}\left(t_{j}\right) \cdot \frac{\sin \beta_{b}}{N_{j, 0}}, \quad 0 \leq t_{j}<t_{0} \\
= & L_{\mathrm{AB}}+\left(v \cdot t_{j}-b \cdot \tan \beta_{b}\right)+i_{0} \cdot L_{0}\left(t_{j}\right) \cdot \frac{\sin \beta_{b}}{N_{j, 0}}, \\
& t_{0} \leq t_{j}<T, \\
R_{e}\left(i_{1}, j\right)= & L_{\mathrm{AB}}+p_{t}-b \cdot \tan \beta_{b}+v \cdot t_{j}+i_{1} \cdot L_{1}\left(t_{j}\right) \cdot \frac{\sin \beta_{b}}{N_{j, 1}}, \\
R_{e}\left(i_{2}, j\right)= & L_{\mathrm{AB}}+2 \cdot t_{j}<T, \\
& \cdot L_{2}\left(t_{j}\right) \cdot \frac{\sin \beta_{b}}{N_{j, 2}}, \quad 0 \leq t_{j}<t_{2} \\
= & 0, \quad t_{2} \leq t_{j}<T .
\end{aligned}
$$

Accordingly, the frictional torque arm for pinion is given by

$$
L_{f}\left(i_{k}, j\right)=R_{e}\left(i_{k}, j\right) \text {. }
$$

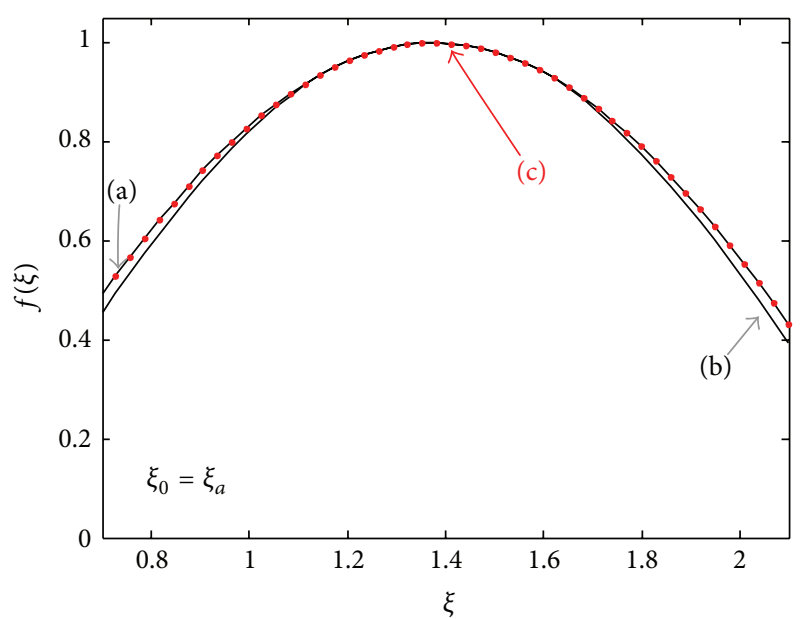

FIGURE 6: Load distribution model verification: (a) integration of elastic potential energy; (b) finite element analysis; (c) current simulation.

The sign convention of the frictional torque is considered as positive when facilitating the rotation and negative otherwise. The friction torque at $i$ th segment of $k$ th tooth pair of pinion at $j$ th meshing instant is calculated as

$$
\begin{gathered}
T_{0}\left(t_{j}\right)=\mu \cdot \Delta l \cdot\left(\sum_{i_{0}=1}^{N_{00}} f_{0}\left(i_{0}, j\right) \cdot L_{f}\left(i_{0}, j\right)\right), \\
0 \leq t_{j}<\frac{\left(f-f_{3}\right)}{v} \\
=\mu \cdot \Delta l \cdot\left(\sum_{i_{0}=1}^{N_{01}} f_{0}\left(i_{0}, j\right) \cdot L_{f}\left(i_{0}, j\right)\right. \\
\left.-\sum_{i_{0}=N_{01}+1}^{N_{0, j}} f_{0}\left(i_{0}, j\right) \cdot L_{f}\left(i_{0}, j\right)\right), \\
\frac{\left(f-f_{3}\right)}{v} \leq t_{j}<T,
\end{gathered}
$$

$$
\begin{aligned}
& T_{1}\left(t_{j}\right)=\mu \cdot \Delta l \cdot\left(\sum_{i_{1}=1}^{N_{11}} f_{1}\left(i_{1}, j\right) \cdot L_{f}\left(i_{1}, j\right)\right. \\
&\left.\quad-\sum_{i_{1}=N_{11}+1}^{N_{1, j}} f_{1}\left(i_{1}, j\right) \cdot L_{f}\left(i_{1}, j\right)\right),
\end{aligned}
$$

$$
\begin{array}{r}
0 \leq t_{j}<T, \\
T_{2}\left(t_{j}\right)=\mu \cdot \Delta l \cdot\left(\sum_{i_{2}=1}^{N_{21}} f_{2}\left(i_{2}, j\right) \cdot L_{f}\left(i_{2}, j\right)\right. \\
\left.\quad-\sum_{i_{2}=N_{21}+1}^{N_{2, j}} f_{2}\left(i_{2}, j\right) \cdot L_{f}\left(i_{2}, j\right)\right),
\end{array}
$$$$
0 \leq t_{j}<T \text {. }
$$ 


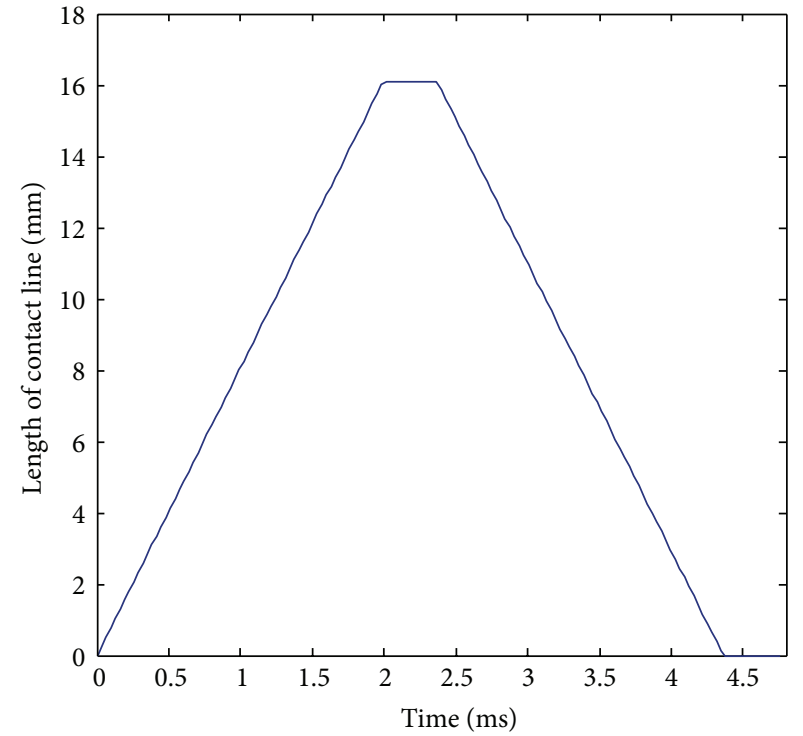

(a)

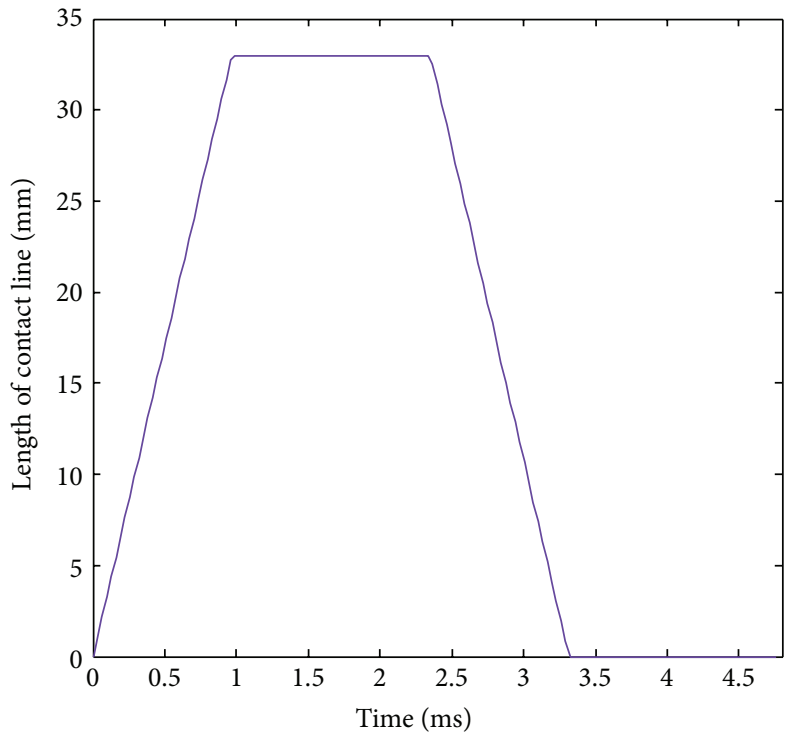

(c)

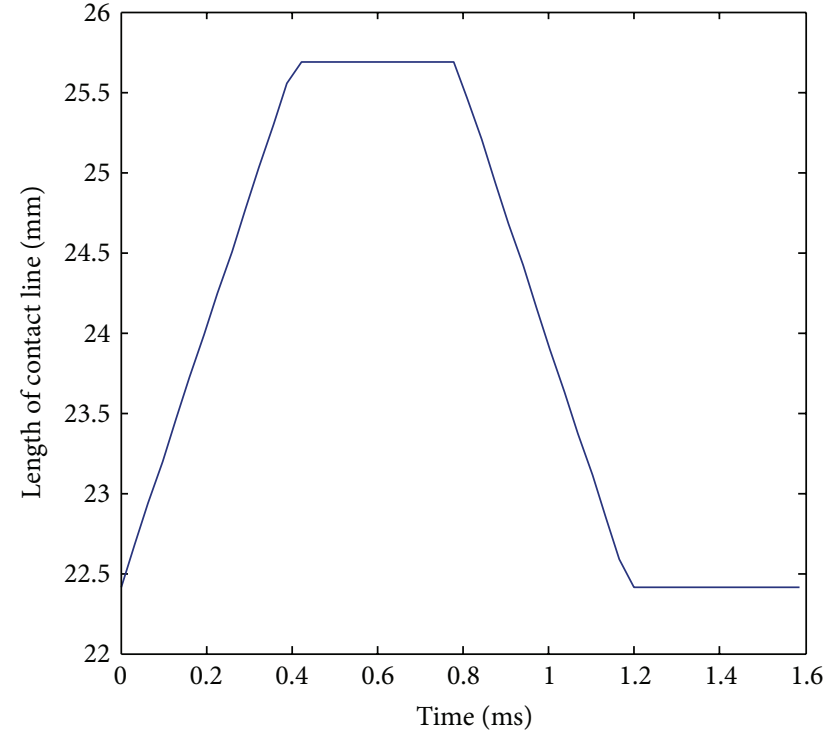

(b)

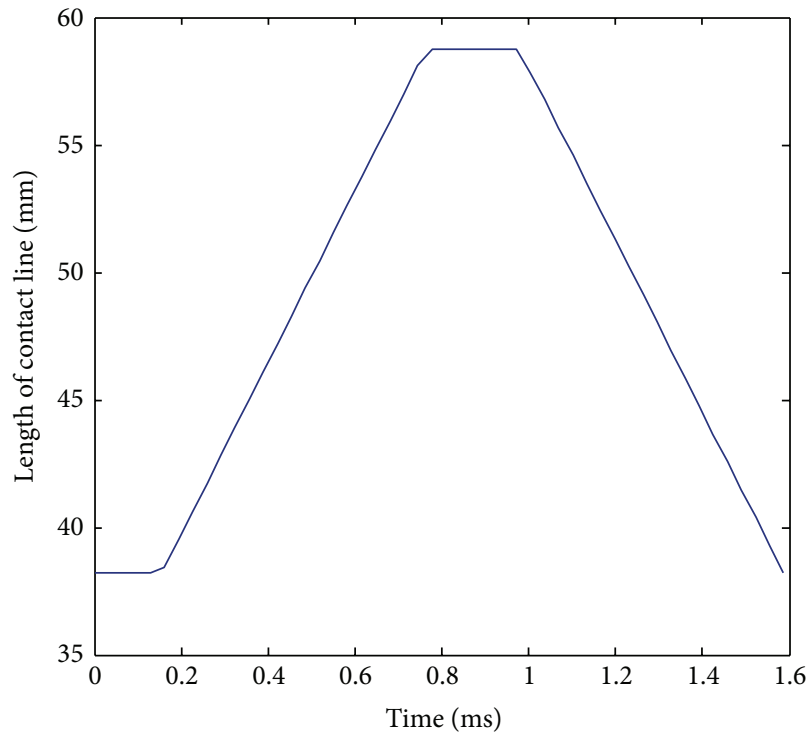

(d)

Figure 7: Time-varying contact lines for (a) single tooth in sample I; (b) three teeth in sample I; (c) single tooth in sample II; (d) three teeth in sample II.

Hence, the total friction torque in three teeth for one transverse pitch travel is given by

$$
T_{f}\left(t_{j}\right)=\sum_{k=0}^{\text {floor }(\varepsilon)} T_{k}\left(t_{j}\right), \quad 0 \leq t_{j}<T
$$

\section{Results and Discussion}

3.1. Model Verification. The load distribution model used in this paper is verified by comparing the results from [13] with the current simulation. The normalized load per unit of length obtained from the finite element analysis, integration of elastic potential energy, and the current model is shown in Figure 6, respectively. The reference transverse section is chosen at $\xi_{0}=\xi_{a}$.

As could be seen from Figure 6, a good agreement is obtained.

3.2. Time-Varying Length of Contact Lines. The simulation parameters used in sample I and II are shown in Tables 1 and 2, respectively. The mesh cycle for one transverse pitch travel is divided into 50 time steps, and $N_{t}=150$. The maximum value of $N_{j, k}$ is 62 in sample I and 60 in sample II corresponding to the maximum length of contact line in both cases. 


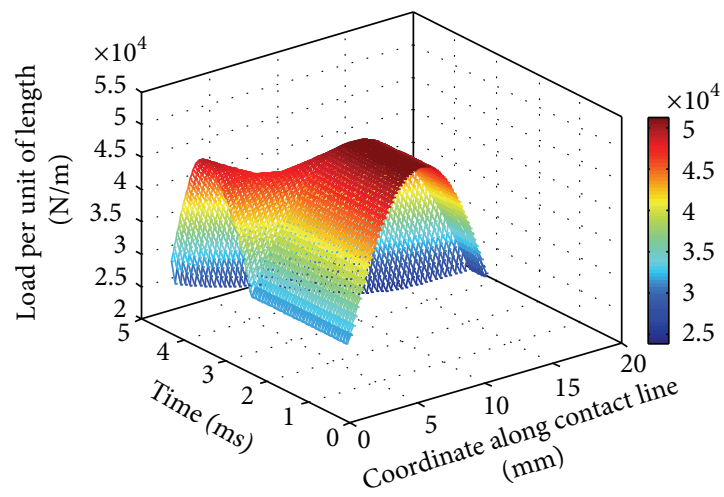

(a)

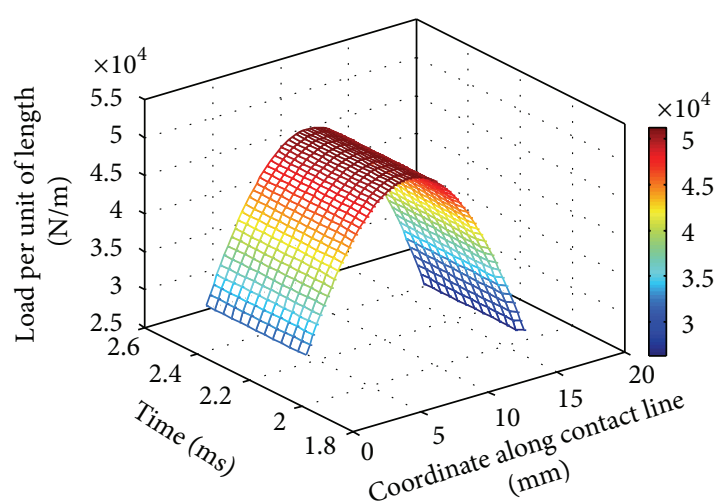

(c)

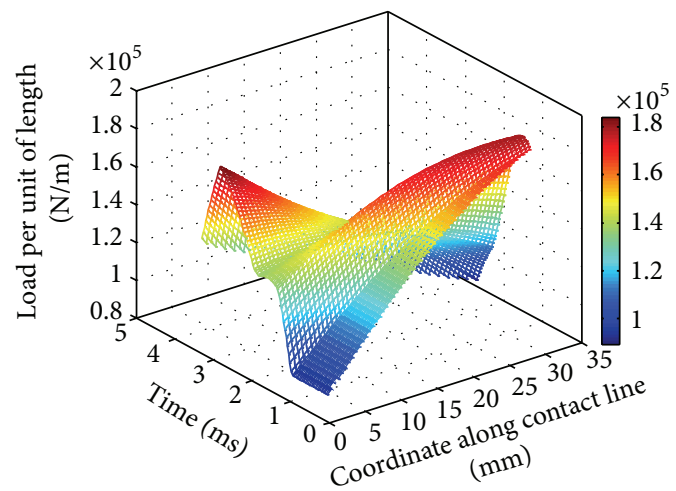

(b)

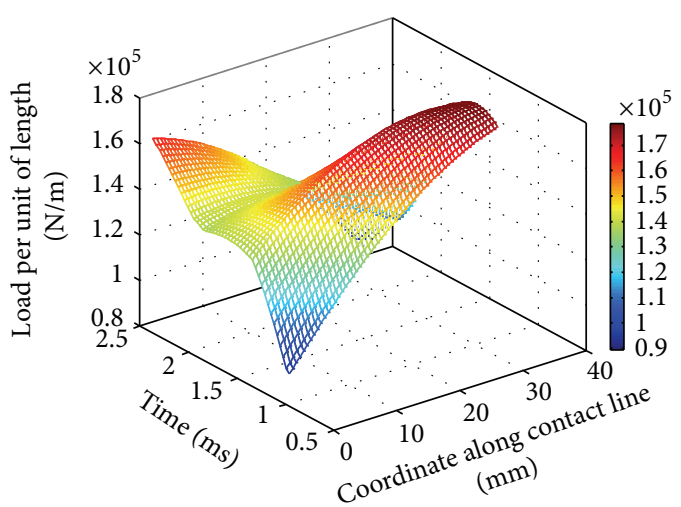

(d)

Figure 8: Load distribution for a single tooth: (a) in a mesh cycle of sample I; (b) in a mesh cycle of sample II; (c) in time interval $t$ (63) $\sim t$ (75) of sample I; (d) in time interval $t(31) \sim t$ (75) of sample II.

TABLE 1: Specifications of helical gear pair for sample I.

\begin{tabular}{lcc}
\hline Item & Pinion & Gear \\
\hline Addendum circle diameter $(\mathrm{mm})$ & 57.2262 & 77.5462 \\
Pitch circle diameter $(\mathrm{mm})$ & 53.34 & 73.66 \\
Number of teeth & 21 & 29 \\
Rotational speed $(\mathrm{Hz})$ & 30 & 21.72 \\
Base width $(\mathrm{mm})$ & \multicolumn{2}{c}{14.986} \\
Helix angle $\left(^{\circ}\right)$ & \multicolumn{3}{c}{$40^{\circ}$} \\
Pressure angle $\left(^{\circ}\right)$ & \multicolumn{3}{c}{$14.5^{\circ}$} \\
Transverse contact ratio & \multicolumn{3}{c}{1.4146} \\
Axial contact ratio & \multicolumn{3}{c}{1.5758} \\
Total contact ratio & \multicolumn{3}{c}{2.9905} \\
Applied torque $(\mathrm{N} \cdot \mathrm{m})$ & \multicolumn{3}{c}{29.1} \\
\hline
\end{tabular}

The time-varying length of contact line for a single tooth in sample I is shown in Figure 7(a). There is a good agreement with the function formulated by Velex and Sainsot [3].

The maximum value of the contact line is $f \operatorname{cosec} \beta_{b}$, while the maximum length of contact line in sample II is $b \sec \beta_{b}$, as shown in Figure 7(c). The variations of total contact lengths for one transverse pitch travel in both cases are shown in Figures 7(b) and 7(d), respectively. As could be
TABLE 2: Specifications of helical gear for sample II.

\begin{tabular}{|c|c|c|}
\hline Item & Pinion & Gear \\
\hline Number of teeth & 21 & 49 \\
\hline Normal pressure angle & & \\
\hline Helix angle $\left({ }^{\circ}\right)$ & & \\
\hline Module (mm) & & \\
\hline Face width $(\mathrm{mm})$ & & \\
\hline Transverse contact ratio & & \\
\hline Axial contact ratio & & \\
\hline Total contact ratio & & \\
\hline Applied torque $(\mathrm{N} \cdot \mathrm{m})$ & & \\
\hline
\end{tabular}

seen from the figure, the time intervals for minimum total length of contact lines differ from each other.

3.3. Load Distribution. In [10], uniform load distribution is assumed, while the load per unit of length varies with different position along contact line.

The load distributions for a single tooth of both samples in a complete cycle are shown in Figures 8(a) and 8(b). As could be seen from the figure, the $x$-axis represents the 

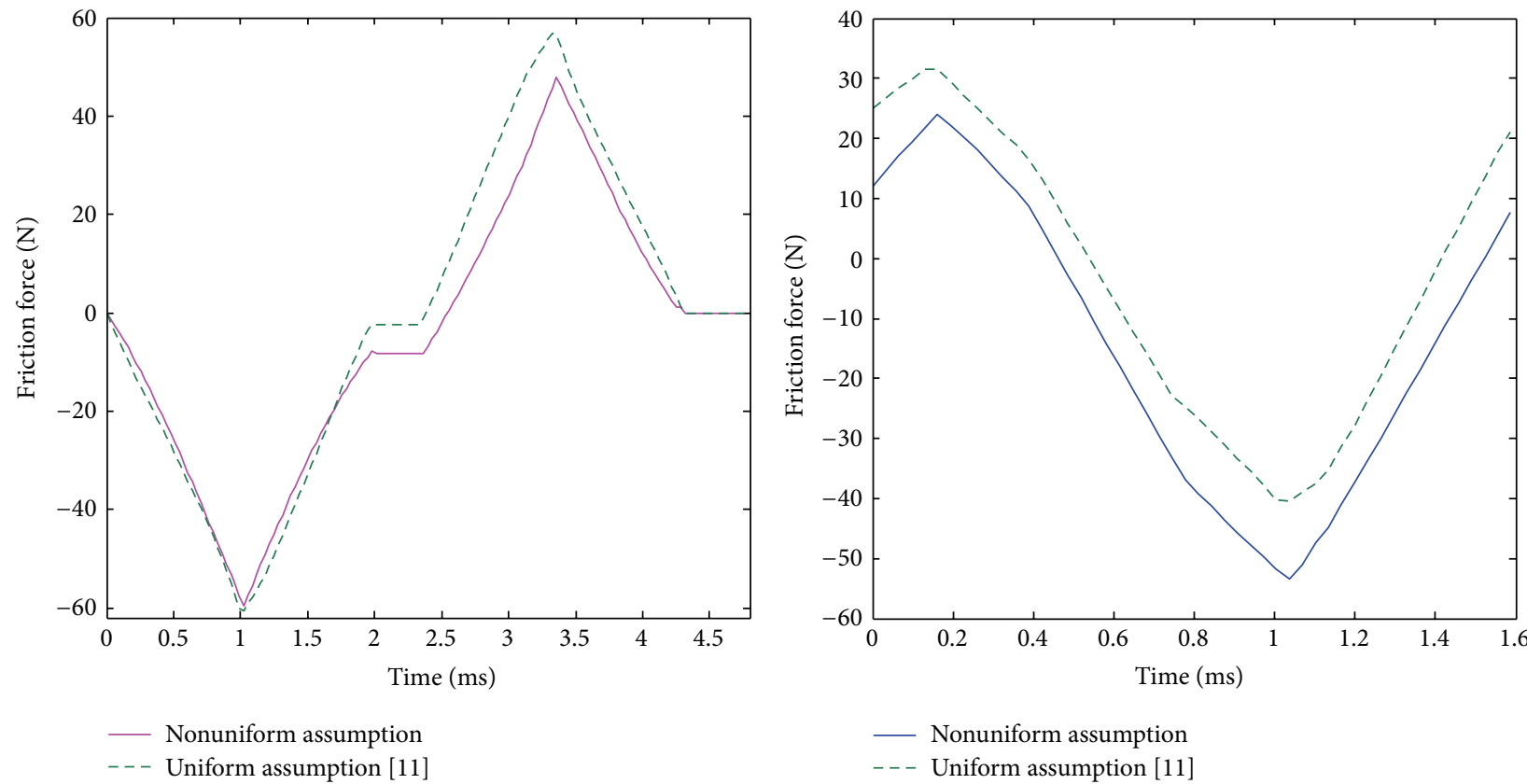

(b)

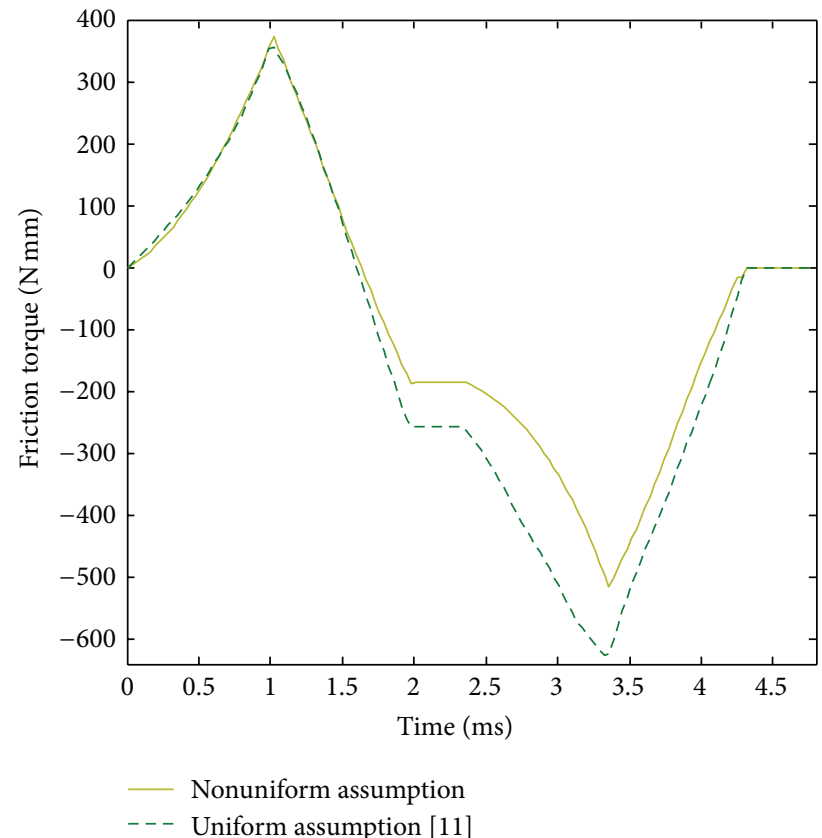

(c)

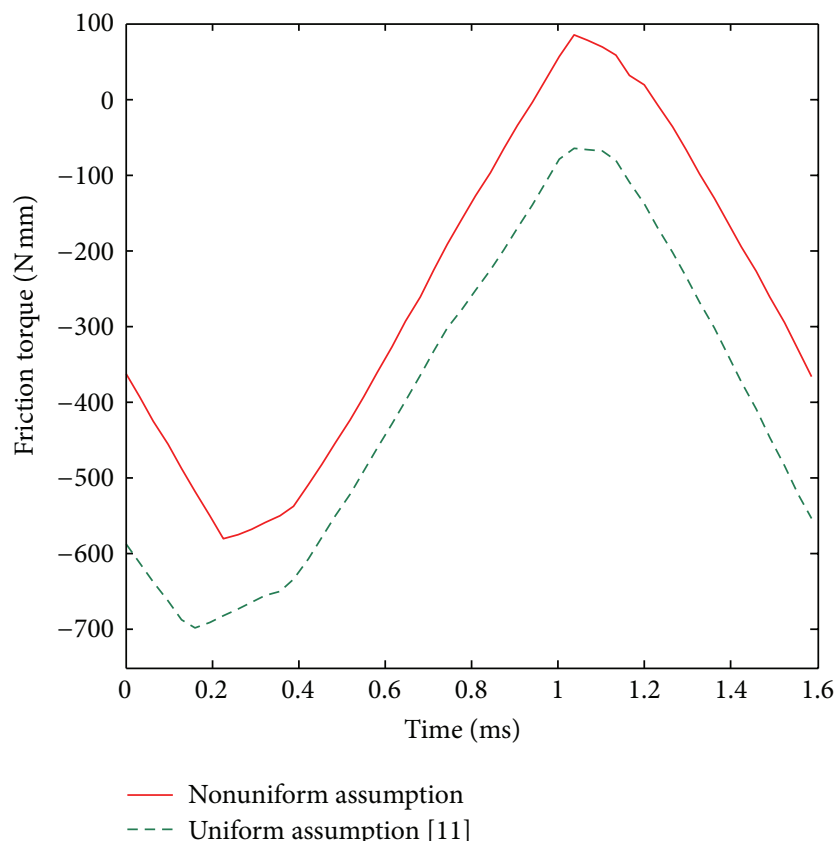

(d)

FIGURE 9: Friction force and torque in sample I: (a) friction force of a single tooth; (b) friction force of three teeth; (c) friction torque of a single tooth; (d) friction torque of three teeth.

TABLE 3: Statistical values of Figure 9.

\begin{tabular}{|c|c|c|c|c|c|c|}
\hline \multirow{2}{*}{ Item } & \multicolumn{2}{|c|}{ Maximum } & \multicolumn{2}{|c|}{ Minimum } & \multicolumn{2}{|c|}{ Mean } \\
\hline & Uniform & Nonuniform & Uniform & Nonuniform & Uniform & Nonuniform \\
\hline Contact length $(\mathrm{mm})$ & \multicolumn{2}{|c|}{25.7} & \multicolumn{2}{|c|}{22.4} & \multicolumn{2}{|c|}{24.0} \\
\hline Friction force $(\mathrm{N})$ & 31.3 & 24.0 & -40.4 & -53.5 & -3.8 & -14.5 \\
\hline Frictional torque $(\mathrm{N} \mathrm{mm})$ & -104.9 & 85.3 & -733.5 & -579.6 & -424.2 & -254.2 \\
\hline
\end{tabular}



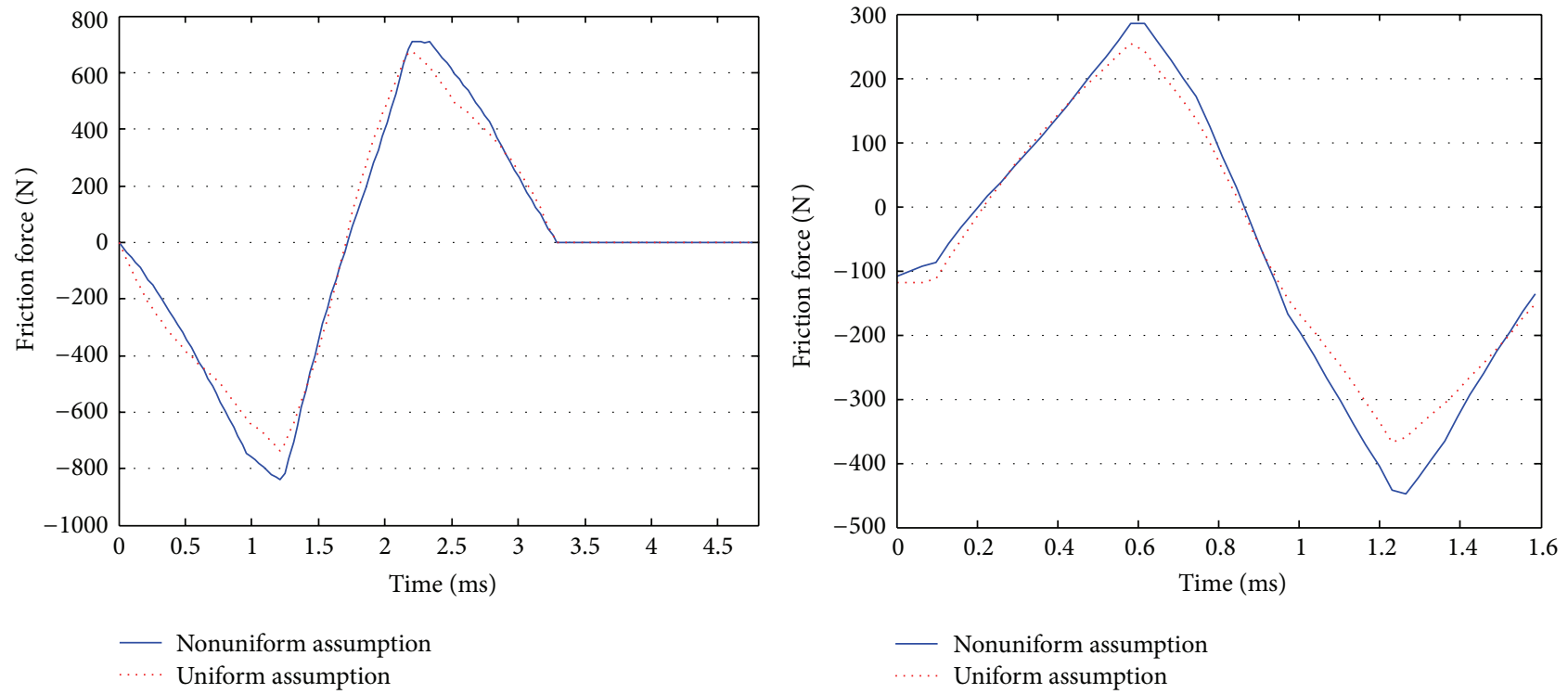

(a)

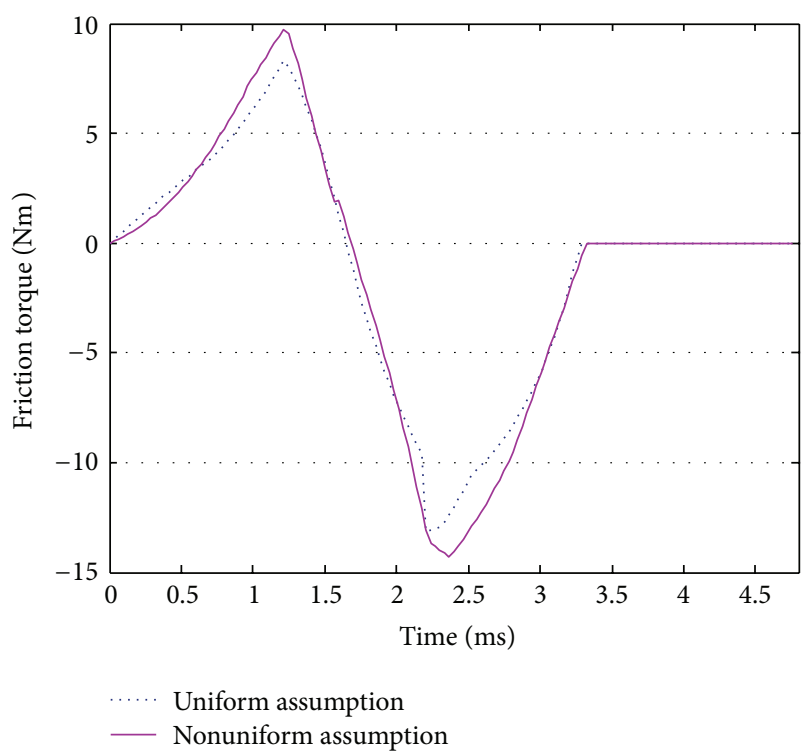

(c)

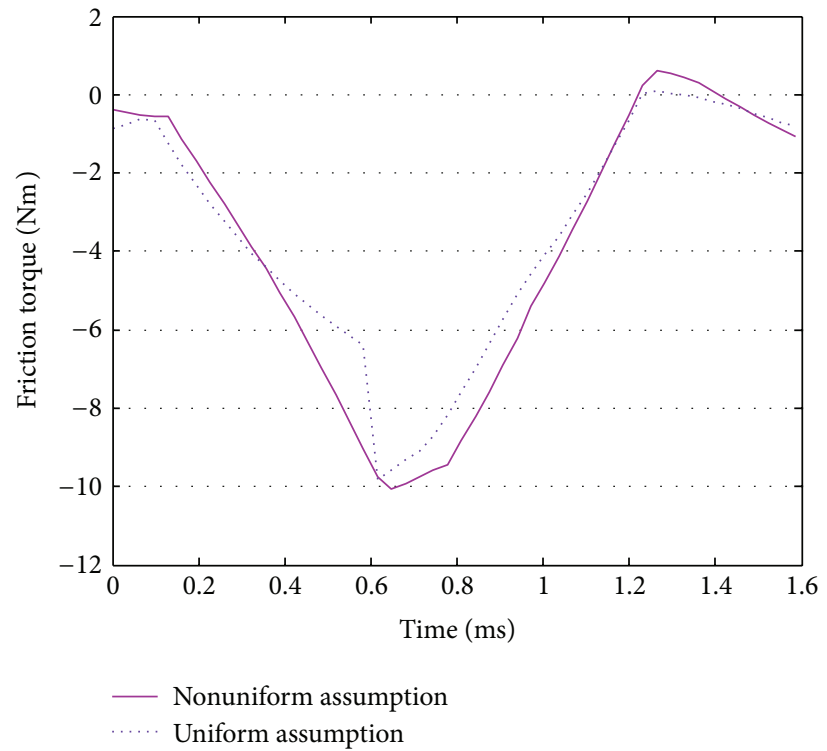

(d)

FIGURE 10: Results for sample II: (a) friction force for a single tooth; (b) friction force for three teeth; (c) friction torque for a single tooth; (d) friction torque for three teeth.

TABLE 4: Statistical values of Figure 10.

\begin{tabular}{|c|c|c|c|c|c|c|}
\hline \multirow{2}{*}{ Item } & \multicolumn{2}{|c|}{ Maximum } & \multicolumn{2}{|c|}{ Minimum } & \multicolumn{2}{|c|}{ Mean } \\
\hline & Uniform & Nonuniform & Uniform & Nonuniform & Uniform & Nonuniform \\
\hline Contact length $(\mathrm{mm})$ & \multicolumn{2}{|c|}{58.7} & \multicolumn{2}{|c|}{38.2} & \multicolumn{2}{|c|}{48.6} \\
\hline Friction force $(\mathrm{N})$ & 167.2 & 189.2 & -243.1 & -297.2 & -41.8 & -46.8 \\
\hline Frictional torque $(\mathrm{N} \mathrm{m})$ & 0.06 & 0.4 & -6.5 & -6.7 & -2.3 & -2.6 \\
\hline
\end{tabular}



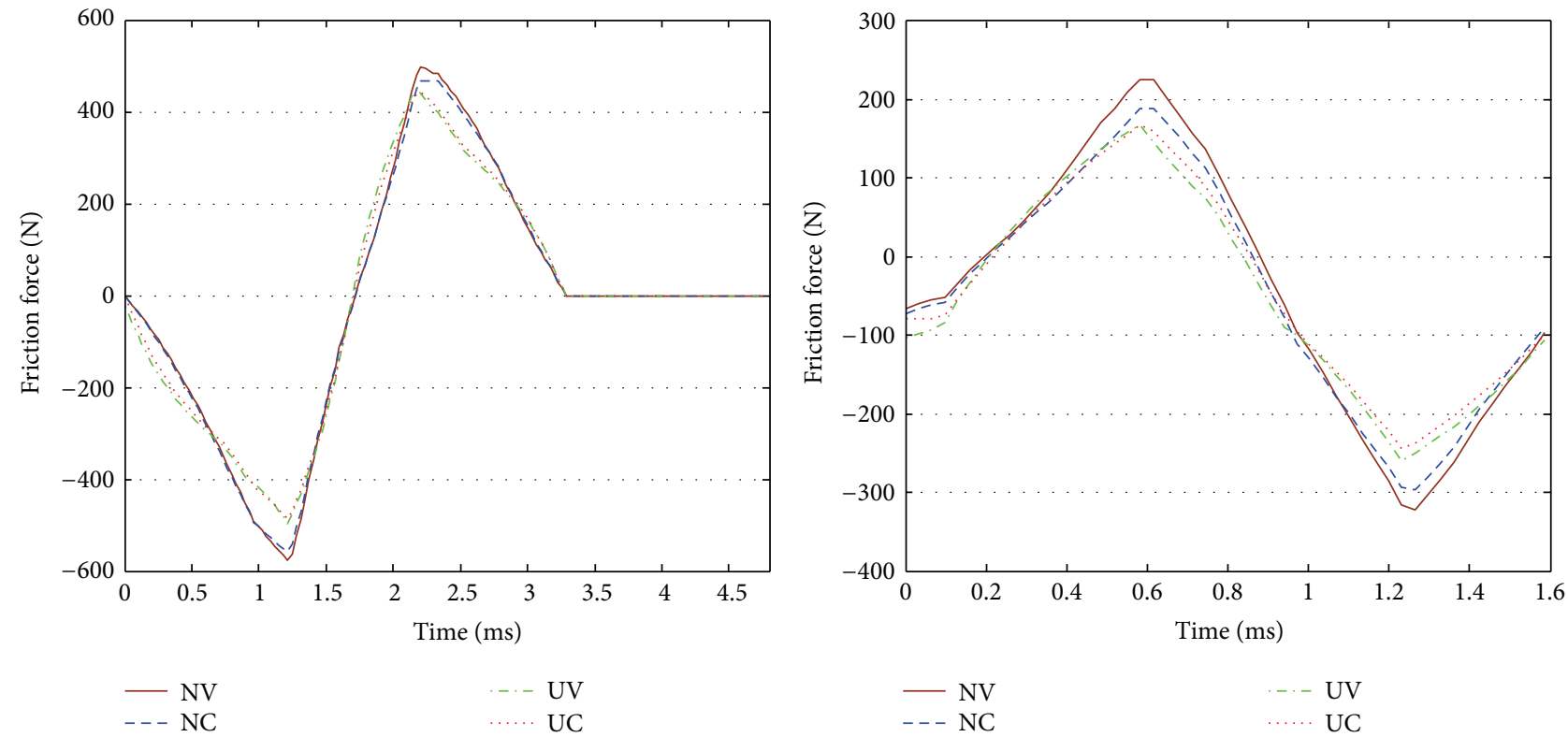

(a)

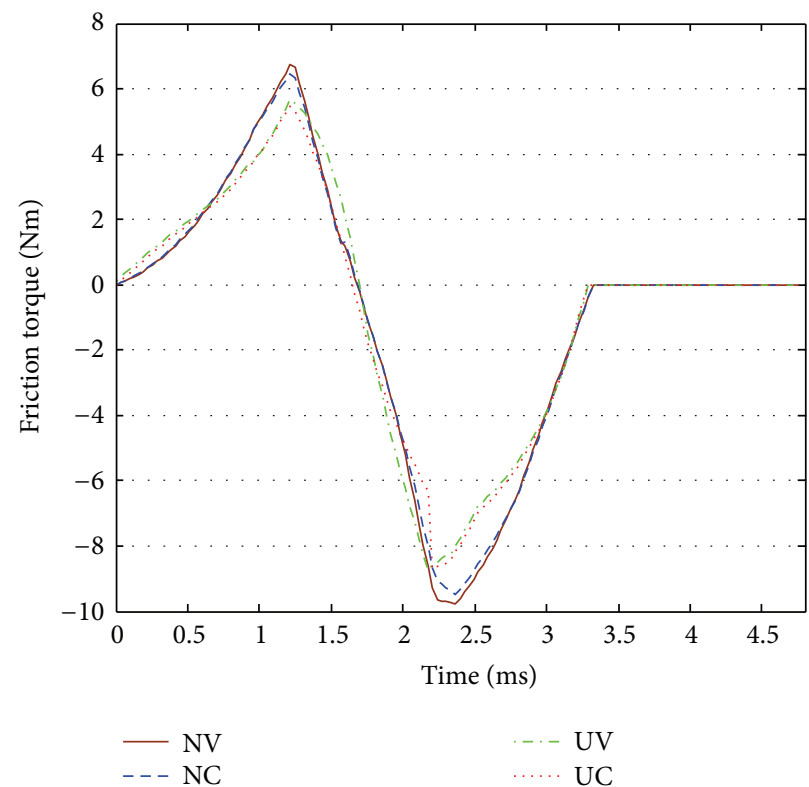

(c)

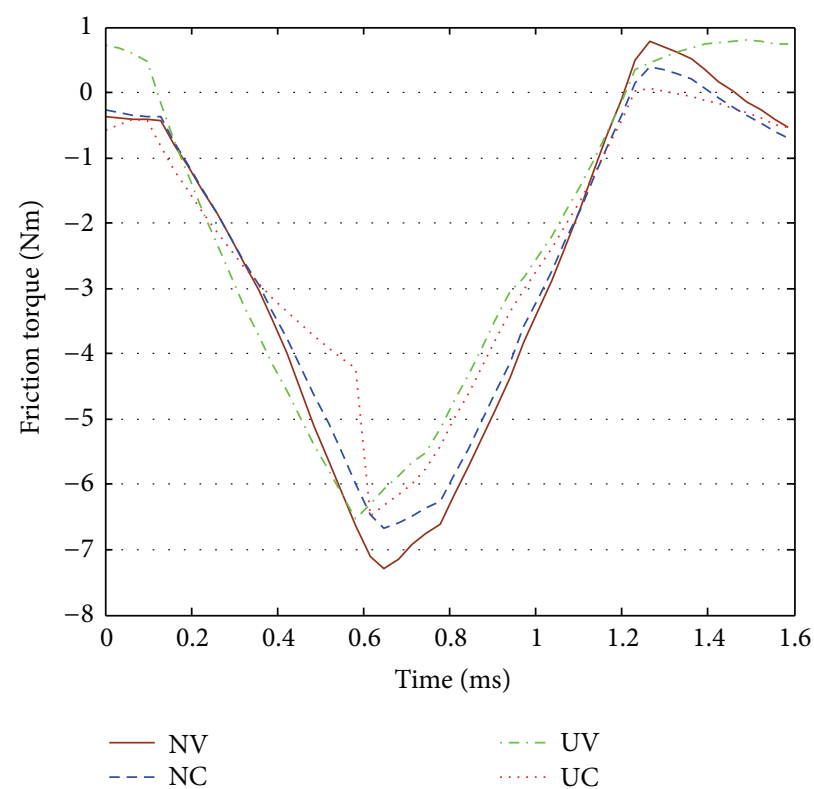

(d)

FIGURE 11: Results for sample II with varying friction coefficient: (a) friction force of a single tooth; (b) friction force of three teeth; (c) friction torque of a single tooth; (d) friction torque of three teeth.

coordinate along instantaneous contact line, while the $y$ axis represents meshing time for a single tooth in three transverse pitch travels. And $z$-axis means the load per unit of length along contact line. Obviously, the distributions in two design cases are different. To make the difference clear, the load distributions during the time interval that contact lines reach maximum values and keep constant are also presented, as shown in Figures $8(\mathrm{c})$ and $8(\mathrm{~d})$. It is indicated that the maximum load per unit of length in sample I lies in the middle part of a contact line, while that in sample II lies in one of the faces of gear.
3.4. Friction Force and Torque. Friction force and torque for both a single tooth and three teeth are shown in Figure 9. As could be seen from the figure, the friction force is not sinusoidal though periodic, similar to the case in spur gear [15]. The dashed lines represent the friction forces obtained under uniform load distribution assumption, while the solid lines represent the results from nonuniform assumption.

For a single tooth, the force difference under two assumptions is trivial before the time when contact line reaches its maximum value. However, the difference becomes significant during the left time in a whole meshing cycle. Different from 
those of a single tooth, there is always a significant difference between the total friction forces under two assumptions for a transverse pitch travel. The statistical values of Figure 9 are shown in Table 3. It shows that the fluctuation under uniform assumption is more significant than that under nonuniform assumption.

Friction torques for a single tooth and three teeth are shown in Figures 9(c) and 9(d), respectively. Similar to friction force, torque fluctuation under uniform assumption is more significant than that under nonuniform assumption. To be noted, as could be seen from Figure 9(d), the peak value of friction torque under nonuniform assumption is positive, while that under uniform assumption is negative. Those differences may result in a different dynamic response in helical gear systems.

Results are shown in Figure 10 and statistical values of the figure are shown in Table 4. Obviously, the fluctuations of both friction force and torque under uniform assumption are less significant than those under nonuniform assumption, which is contrary to sample I. The short constant force interval appearing in the first sample does not come out in this one.

3.5. Results from Time-Varying Friction Coefficient. To investigate the influence of time-varying friction coefficient on the resultant friction force and torque, a friction coefficient formula proposed by [14] is employed as

$$
\mu_{k}\left(i_{k}, j\right)=\frac{0.0127 \times 1.13}{1.13-S_{\text {avg }}} \log _{10}\left[\frac{29700 f_{k}\left(i_{k}, j\right)}{\eta v_{s}\left(i_{k}, j\right) v_{e}^{2}\left(i_{k}, j\right)}\right],
$$

where $S_{\text {avg }}$ is the averaged surface roughness, and $\eta$ is the dynamic viscosity of the oil entering the gear contact. $v_{s}\left(i_{k}, j\right)$ and $v_{e}\left(i_{k}, j\right)$ represent the sliding velocity and the entraining velocity of the $i$ th segment of $k$ th tooth pair at $j$ th meshing instant, respectively, as

$$
\begin{gathered}
v_{s}\left(i_{k}, j\right)=\left|v_{p}\left(i_{k}, j\right)-v_{g}\left(i_{k}, j\right)\right|, \\
v_{e}\left(i_{k}, j\right)=\left|v_{p}\left(i_{k}, j\right)+v_{g}\left(i_{k}, j\right)\right|, \\
v_{p}\left(i_{k}, j\right)=\omega_{p} R_{p e}\left(i_{k}, j\right), \\
v_{g}\left(i_{k}, j\right)=\omega_{g} R_{g e}\left(i_{k}, j\right),
\end{gathered}
$$

where $R_{p e}\left(i_{k}, j\right)$ is the radii of curvature at each segment of pinion as given by (16), and $R_{g e}\left(i_{k}, j\right)$ is the radii of curvature at corresponding contact segment of gear and is given by

$$
R_{g e}\left(i_{k}, j\right)=\left(r_{b}+R_{b}\right) \tan \alpha_{t}-R_{p e}\left(i_{k}, j\right) .
$$

Here, only sample II is taken as an example. The legends NV, NC, UV, and UC in Figure 11 denote the results from nonuniform load distribution and varying friction coefficient assumption; nonuniform load distribution and constant friction coefficient assumption; uniform load distribution and varying friction coefficient assumption; uniform load distribution and constant friction coefficient assumption, respectively. The constant friction coefficient is obtained by averaging the time-varying coefficients calculated by (20).
As could be seen from Figures 11(a) and 11(b), the friction forces under NV assumption and NC assumption are very close to each other; similarly, the force difference between UV assumption and UC assumption is negligible. However, it is obvious that there is a nonnegligible difference between uniform and nonuniform load distribution assumption, which means that the force fluctuation under nonuniform assumption is more significant than that under uniform assumption. A similar conclusion could be made on frictional torque, as shown in Figures 11(c) and 11(d).

\section{Conclusion}

This paper proposed an improved algorithm to calculate the friction force and torque in helical gear pairs, considering the nonuniform load distribution along contact lines. Two design samples are studied. In sample I, the maximum load per unit of length lies in the middle area of a contact line, while that in sample II lies in one of the faces of gear. The fluctuations of friction force and torque under uniform assumption in the first sample for a single tooth is more significant than those under nonuniform assumption, while the sum of friction force and torque for three teeth are less significant. On the contrary, the fluctuations of both friction force and torque under uniform assumption in the second sample are less significant than those under nonuniform assumption for both a single tooth and the sum of the three teeth. Compared with the difference induced by uniform and nonuniform load distribution assumptions, the differences induced by different friction coefficient models are negligible. Those differences may result in a different dynamics response in a geared system. In addition, both friction coefficient and applied load are linearly proportional to the difference between the fluctuations of friction force and torque obtained under two assumptions. The work presented here provides a way for further dynamics analysis for gear systems.

\section{Nomenclature}

$\begin{array}{ll}b: & \text { Gear width } \\ b_{0}: & \text { Auxiliary parameter } \\ d_{\alpha}: & \text { Decimal fraction of } \varepsilon_{\alpha} \\ d_{\beta}: & \text { Decimal fraction of } \varepsilon_{\beta} \\ E_{\gamma}: & \text { Integer part of } \varepsilon \\ f: & \text { Length of contact zone } \\ f_{1}, f_{2}, f_{3}, f_{4}: & \text { Length parameters in contact } \\ & \text { zone shown in Figure } 2 \\ f_{k}\left(i_{k}, j\right): & \text { Load per unit of length } \\ F: & \text { Applied load } \\ F_{k}: & \text { Friction force of } k \text { th tooth } \\ F_{f}: & \text { Total friction force of three teeth } \\ F_{\text {uni }}: & \text { Force from uniform assumption } \\ F_{\text {non }}: & \text { Force from nonuniform } \\ I_{v}: & \text { assumption } \\ L: & \text { Sum of inverse unitary potential } \\ & \text { Total length of three contact } \\ & \text { lines }\end{array}$




\begin{tabular}{|c|c|}
\hline$L_{f}:$ & Frictional torque arm \\
\hline$L_{i}:$ & Length of $i$ th contact line \\
\hline$L_{i j}:$ & $j$ th segment on $i$ th contact line \\
\hline$\Delta l:$ & Length of each segment \\
\hline$N_{j, k}:$ & $\begin{array}{l}\text { Number of segments of } k \text { th } \\
\text { tooth at } j \text { th instant }\end{array}$ \\
\hline$N_{t}:$ & Total time steps \\
\hline$N_{00}, N_{01}, N_{11}, N_{21}:$ & $\begin{array}{l}\text { Number of segments on line } \\
\text { segments }\end{array}$ \\
\hline$p_{t}:$ & Pitch in transverse plane \\
\hline$p_{b t}:$ & Base pitch in transverse plane \\
\hline$r:$ & $\begin{array}{l}\text { Reference radius shown in } \\
\text { Figure } 3\end{array}$ \\
\hline$r_{a 1}:$ & Radius of addendum circle \\
\hline$r_{b 1}:$ & Radius of base circle \\
\hline$R_{b}:$ & Radius of base circle of gear \\
\hline$R_{e}\left(i_{k}, j\right):$ & $\begin{array}{l}\text { Radius of curvature at each } \\
\text { segment }\end{array}$ \\
\hline$t:$ & Meshing time \\
\hline$t_{11}, t_{12}, t_{0}, t_{2}, t_{21}:$ & $\begin{array}{l}\text { Time instant corresponding to } \\
\text { meshing position }\end{array}$ \\
\hline$T:$ & Meshing period for a pitch travel \\
\hline$T_{f}:$ & Frictional torque of three teeth \\
\hline$T_{k}:$ & Frictional torque of $k$ th tooth \\
\hline$v:$ & Linear speed along line of action \\
\hline$v(\zeta):$ & Inverse unitary potential \\
\hline$z:$ & Number of teeth \\
\hline$\beta_{b}:$ & Base helix angle \\
\hline$\varepsilon:$ & $\begin{array}{l}\text { Total contact ratio of helical } \\
\text { gears }\end{array}$ \\
\hline$\varepsilon_{\alpha}:$ & Transverse contact ratio \\
\hline$\varepsilon_{\beta}:$ & Axial contact ratio \\
\hline$\zeta:$ & Auxiliary parameter \\
\hline$\zeta_{0}:$ & Auxiliary parameter \\
\hline$\mu:$ & Friction coefficient \\
\hline$\xi$ & Profile parameter \\
\hline$\xi_{\text {inn }}:$ & $\begin{array}{l}\text { Profile parameter corresponding } \\
\text { to the inner contact point of } \\
\text { pinion }\end{array}$ \\
\hline$\omega:$ & Rotational speed of gears \\
\hline$\omega_{p}:$ & Rotational speed of pinion. \\
\hline
\end{tabular}

\section{Acknowledgment}

This work was supported by the National Science and Technology Major Projects of China (Grant no. 2012ZX04012031).

\section{References}

[1] O. Lundvall, N. Stromberg, and A. Klarbring, "A flexible multi-body approach for frictional contact in spur gears," Journal of Sound and Vibration, vol. 278, no. 3, pp. 479-499, 2004.

[2] P. Velex and V. Cahouet, "Experimental and numerical investigations on the influence of tooth friction in spur and helical gear dynamics," Journal of Mechanical Design, vol. 122, no. 4, pp. 515-522, 2000.
[3] P. Velex and P. Sainsot, "An analytical study of tooth friction excitations in errorless spur and helical gears," Mechanism and Machine Theory, vol. 37, no. 7, pp. 641-658, 2002.

[4] I. Howard, S. Jia, and J. Wang, "The dynamic modelling of a spur gear in mesh including friction and a crack," Mechanical Systems and Signal Processing, vol. 15, no. 5, pp. 831-853, 2001.

[5] M. Vaishya and R. Singh, "Sliding friction-induced nonlinearity and parametric effects in gear dynamics," Journal of Sound and Vibration, vol. 248, no. 4, pp. 671-694, 2001.

[6] S. He, R. Gunda, and R. Singh, "Effect of sliding friction on the dynamics of spur gear pair with realistic time-varying stiffness," Journal of Sound and Vibration, vol. 301, no. 3-5, pp. 927-949, 2007.

[7] S. He, S. Cho, and R. Singh, "Prediction of dynamic friction forces in spur gears using alternate sliding friction formulations," Journal of Sound and Vibration, vol. 309, no. 3-5, pp. 843851, 2008.

[8] M. Maatar and P. Velex, "An analytical expression for the time-varying contact length in perfect cylindrical gears: some possible applications in gear dynamics," Journal of Mechanical Design, vol. 118, no. 4, pp. 586-589, 1996.

[9] M. Vaishya and R. Singh, "Strategies for modeling friction in gear dynamics," Journal of Mechanical Design, vol. 125, no. 2, pp. 383-393, 2003.

[10] S. He, R. Gunda, and R. Singh, "Inclusion of sliding friction in contact dynamics model for helical gears," Journal of Mechanical Design, vol. 129, no. 1, pp. 48-57, 2007.

[11] C. Kar and A. R. Mohanty, "An algorithm for determination of time-varying frictional force and torque in a helical gear system," Mechanism and Machine Theory, vol. 42, no. 4, pp. 482496, 2007.

[12] C. Kar and A. R. Mohanty, "Determination of time-varying contact length, friction force, torque and forces at the bearings in a helical gear system," Journal of Sound and Vibration, vol. 309, no. 1-2, pp. 307-319, 2008.

[13] J. I. Pedrero, M. Pleguezuelos, M. Artés, and J. A. Antona, "Load distribution model along the line of contact for involute external gears," Mechanism and Machine Theory, vol. 45, no. 5, pp. 780794, 2010.

[14] G. H. Benedict and B. W. Kelley, "Instantaneous coefficients of gear tooth friction," Transactions of the American Society of Lubrication Engineer, vol. 4, pp. 59-70, 1961.

[15] H. Iida, A. Tamura, and Y. Yamada, "Vibration characteristics of friction between gear teeth," Bulletin of the Japan Society of Mechanical Engineers, vol. 241, pp. 1512-1519, 1985. 


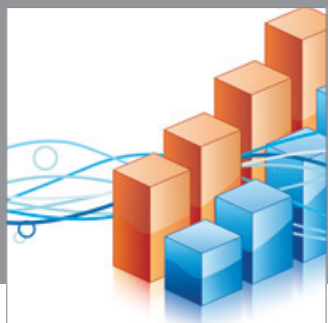

Advances in

Operations Research

mansans

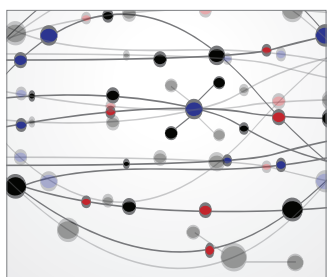

The Scientific World Journal
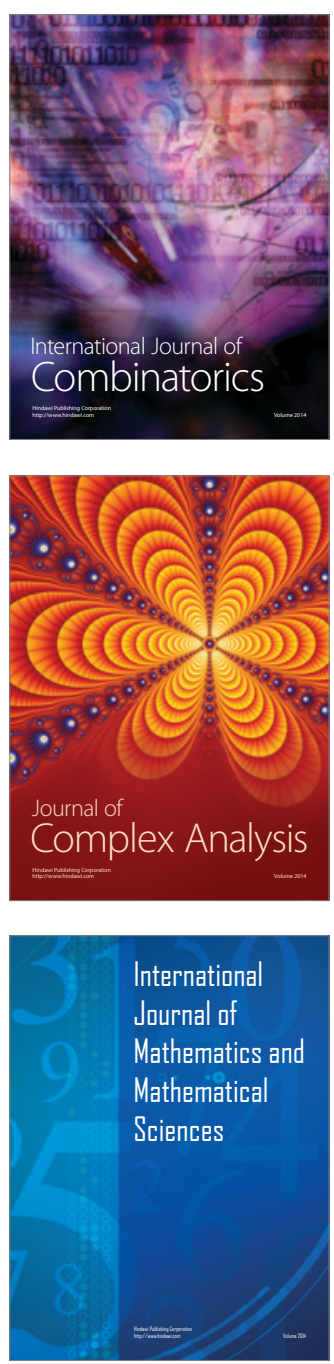
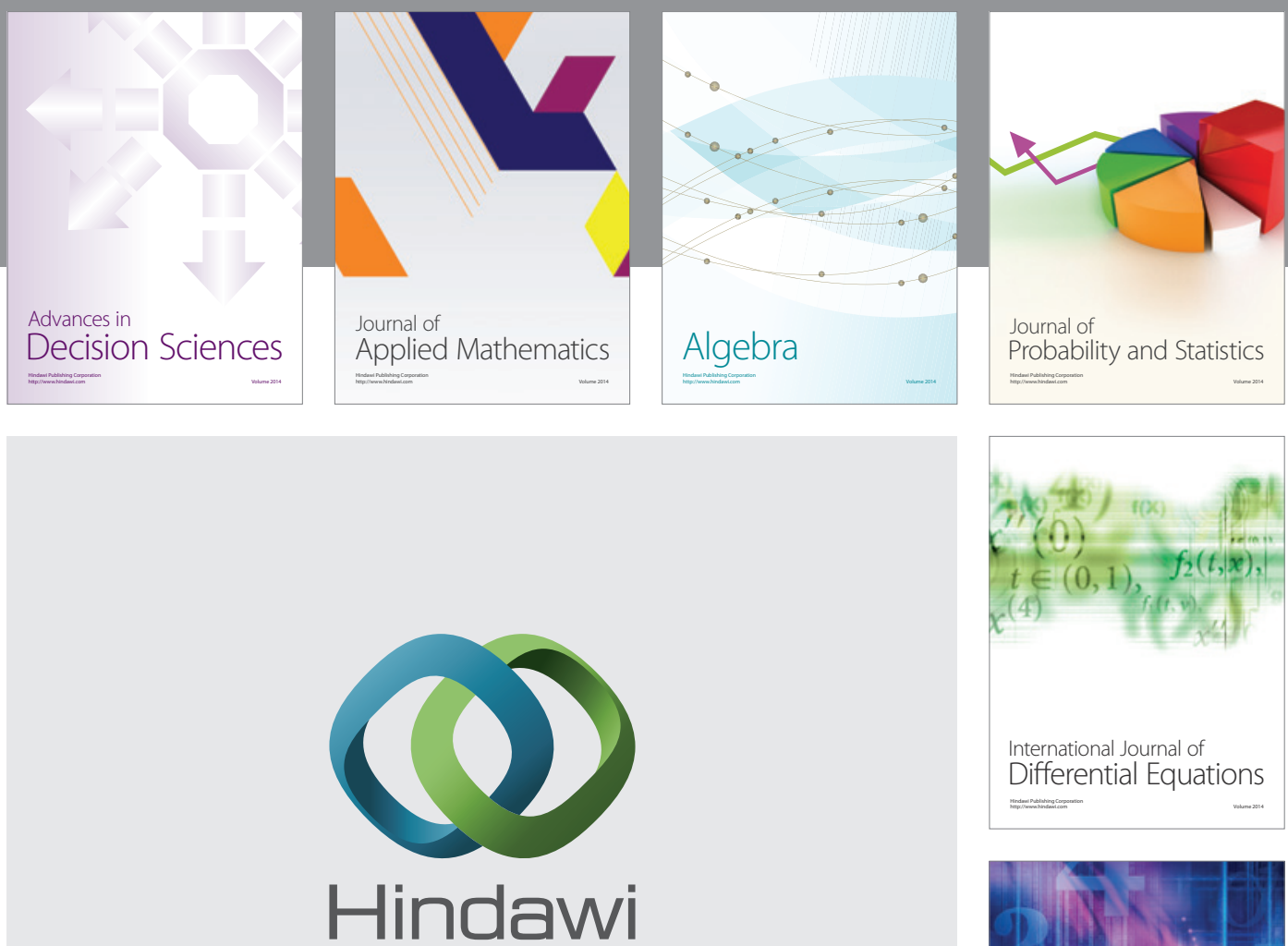

Submit your manuscripts at http://www.hindawi.com
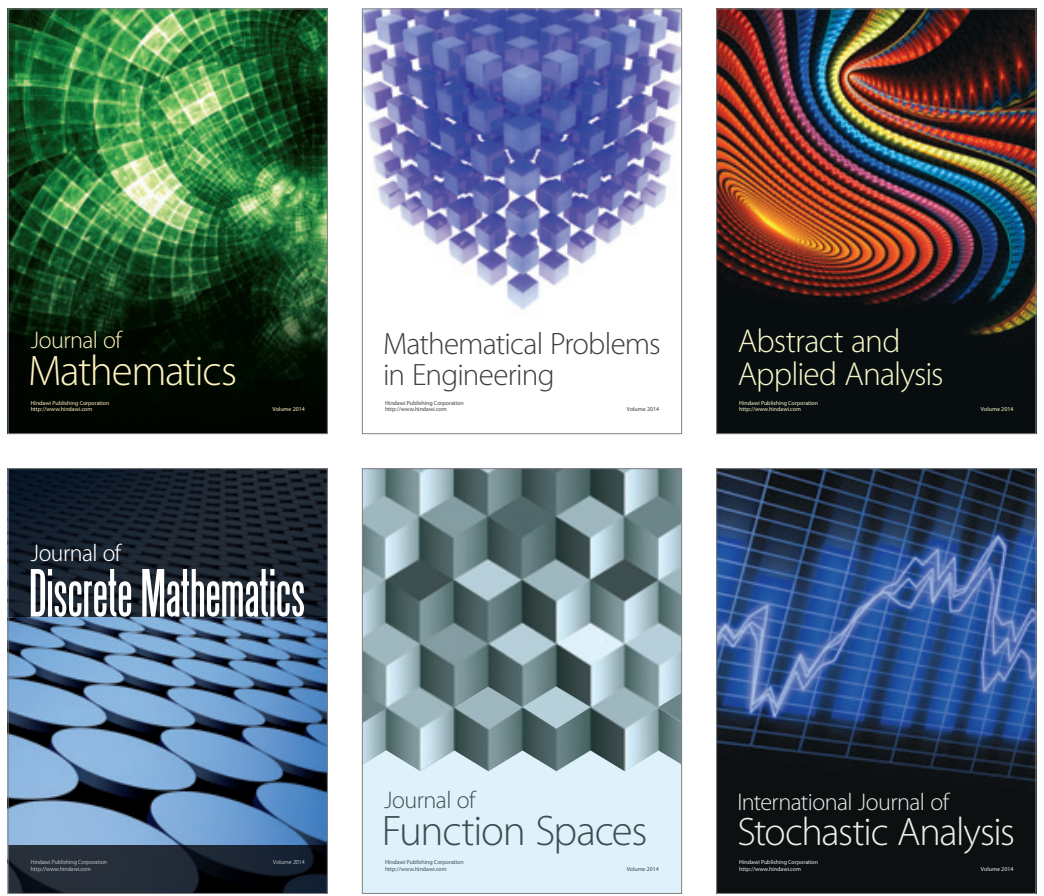

Journal of

Function Spaces

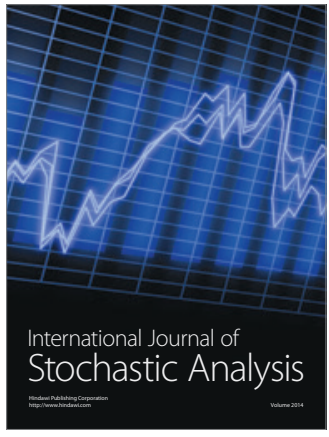

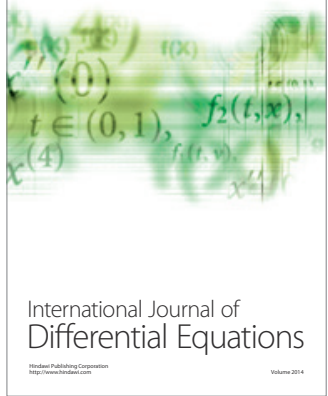
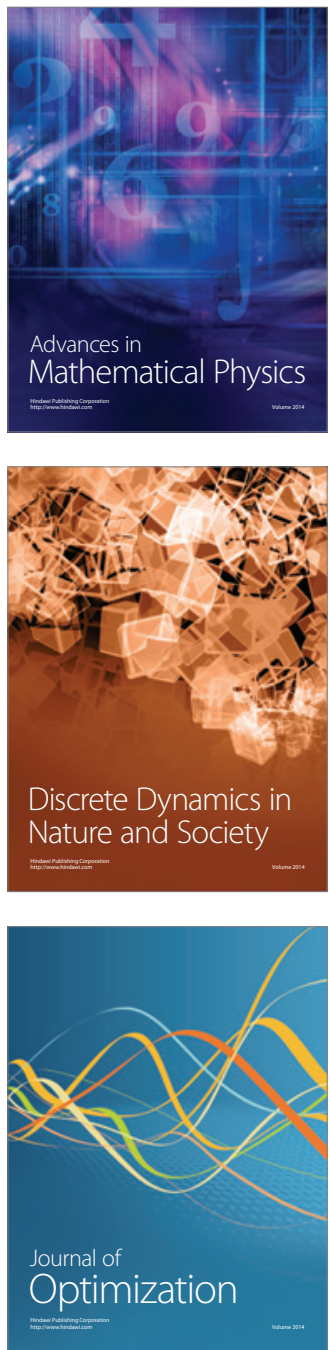